\title{
Protective Effect of Victory Onion (Allium victorialis L.) Extract on Reproductive System Injury in Male Rats
}

\author{
Fanzhu LI ${ }^{1}$, Xian ZHANG $^{1 *}$, Kashif AMEER ${ }^{2}$ Jong-Bang EUN ${ }^{2}$ [0]
}

\begin{abstract}
Aqueous and ethanol extracts of $A$. victorialis were obtained by reflux extraction. A model of kidney yang deficiency as established by injecting hydrocortisone into male Sprague-Dawley rats. The experimental groups ( $\mathrm{n}=8$ rats per group) consisted of blank group, kidney yang deficiency group, and Jingui Shenqi control group (oral administration of Jingui Shenqi herbal preparation). In the treated groups, A. victorialis aqueous or ethanol extract was applied at doses of 1000,800 , or $400 \mathrm{mg} / \mathrm{kg}$. In the model group, kidney yang was associated with loss of appetite, increased drinking water consumption and urine output, and decreased range of activity. With a longer injection time, body weight slowly increased, the body temperature decreased, the response was slow, kyphosis was evident in the back of the bow, and body hair became sparse and lost luster in treated group.
\end{abstract}

Keywords: A. victorialis extract; kidney yang deficiency; reproductive function.

Practical Application: The plant, in past centuries in certain mountainous regions of Europe, "was cultivated as a medicinal and fetish plant". Its extrcat can be used to improve copularoy behaviour as evidenced by rat study.

\section{Introduction}

The genus Allium comprises approximately 600 species. Plants in the genus are widely distributed in northwest United States, Asia, and Europe. Allium victorialis L. is a shrub commonly found in temperate zones of Asia, Europe, Japan, northwest USA, and the mountainous regions of Caucasia and the Himalayas. A. victorialis $\mathrm{L}$. is categorized as the wild onion and is commonly known as victory onion, alpine broad-leaved Allium, and alpine leek (Ji et al., 2018; Nishimura et al., 2006). The plant typically grows on wet and damp slopes, under forest canopies, and in grassland ditches (Tanaka \& Ono, 2018), In China, it is widely distributed in various provinces, including Jilin, Heilongjiang, Liaoning, and Inner Mongolia.

A. victorialis $\mathrm{L}$. has a long history of use for the treatment of colds and profuse menstruation, with reported antioxidant, antiatherogenic, antihyperlipidemic, antiscorbutic, and antithrombotic activities (Khan et al., 2015; Shirataki et al., 2001). As a medicinal herb, A. victorialis $\mathrm{L}$. has been used as a traditional remedy for a variety of ailments, such as arteriosclerosis, stomachache, gastritis, and hypertension. The plant components include allicin, kaempferol, ferulic acid, astragalin, methyl allyl disulfide, quercetin, diallyl disulfide, and furostanol glycosides (Woo et al., 2012). A review of the recent literature suggests the diverse pharmacological efficacies of A. victorialis $\mathrm{L}$. against oxidative stress, cancer, diabetes, and obesity, as well as its hepato- and renal-protective effects (Choi et al., 2005; Lee, 2014). Wild onion is rich in nutrients; it contains protein, fat, sugar, niacin, carotene, minerals (calcium, iron, phosphorus, and potassium), and active ingredients, such as flavonoids, saponins, and alkaloids. The observed biological significance of A. victorialis L. highlighted the need for further study concerning its physiological effects and improvement of sexual function (Shirataki et al., 2001).

In the past decade, the use of natural medicines and natural supplements as complementary and alternative medicines has burgeoned globally. Contemporary studies have shown that sexual dysfunction in males often presents as endocrine system dysfunctions that involve the hypothalamic-pituitary-adrenal (HPA) axis, hypothalamic-pituitary-gonadal (HPG) axis, and hypothalamic-pituitary-thyroid axis. These disorders lead to the insufficient secretion of related hormones, which results in male sexual dysfunction (Corradi et al., 2016). Western medicine, in contrast, views penile erection as being due to vascular and nervous system properties. The rapid regulation of the molecular levels of cyclic adenosine monophosphate (cAMP) and cyclic guanosine monophosphate (cGMP), and the chronic regulation of nucleic acids are considered to play leading roles. Currently, erectile dysfunction is typically treated using synthetic drugs such as sildenafil (most commonly sold as Viagra) and tadalafil (most commonly sold as Cialis). While effective, adverse side effects include headache, muscle ache, and blurred vision, and it has been observed that dangerous interactions with other drugs can occur. Furthermore, these drugs do not increase sexual desire (Sandroni, 2001; Shamloul, 2010). These drawbacks have prompted the search for effective alternate compounds obtained from plants. Data from animal models and human clinical trials have indicated the potential of plant compounds to enhance reproductive function, with the additional benefits of safety and 
minimal side effects compared with synthetic drugs. Research on the application of natural plants to improve damaged reproductive function has intensified (Sumalatha \& Kumar, 2010).

Awareness of health and wellness has increased. At the same time, life and work pressures of the fast-paced modern environment can be detrimental to people. Considering the present research topic, men can suffer from physical fatigue and weakness. This has spurred interest in men for functional foods that tonify the kidney and alleviate impotence. Recent studies have shown that plants of genus Allium contain a variety of active substances with potential benefit in improving reproductive function (Lee et al., 2001). However, no research report has thus far focused on the role of victory onion on the protection and remediation of reproductive damage. The main purpose of this study was to investigate the effects of aqueous and alcohol extracts of A. victorialis L. on sexual behavior and reproductive function of male rats. There are many reasons for sexual dysfunction. The main cause is insufficient relaxation of the corpus cavernosum. Hence, we explored the nitric oxide (NO)-cGMP signaling pathway in the corpus cavernosum. The findings provide a sufficient experimental basis regarding the protective effects of victory onion on reproductive damage, a solid foundation for improving the edible value of victory onions, and a theoretical basis for future development and utilization.

\section{Materials and methods}

\subsection{Test materials and animals}

Wild victory onions were purchased from the Yanbian area of Jilin Province. Male Sprague-Dawley rats approximately 4-months-of-age and $200 \mathrm{~g} \pm 20 \mathrm{~g}$ in body weight were purchased from Liaoning Changsheng Biotechnology Co., Ltd. (license number: SCXK (Liao) 2015-0001). Female Sprague-Dawley rats approximately 3 -months-of-age and $220 \mathrm{~g} \pm 20 \mathrm{~g}$ in body weight were purchased from the Yanbian University Animal Testing Center. The rats were housed in clean and naturally-lit metabolic cages with an indoor temperature of $22-26^{\circ} \mathrm{C}$, and humidity of $40-50 \%$. The rats were fed a commercial diet.

\subsection{Experimental equipment}

The instruments and equipment required for the test are summarized in Supplementary Material Table S1.

\subsection{Experimental drugs and kits}

The drugs and reagents used are summarized in Supplementary Table S2.

\subsection{Preparation of aqueous extract of victory onions}

Water extraction was carried out by soaking $1 \mathrm{~kg}$ of fresh leaves in $15 \mathrm{~L}$ of distilled water for $24 \mathrm{~h}$ and then refluxing for $2 \mathrm{~h}$. The extract was frozen at $-80^{\circ} \mathrm{C}$ for $4 \mathrm{~h}$, and then mechanically freeze-dried for $48 \mathrm{~h}$. The extract was ground into powder and stored frozen at $-20^{\circ} \mathrm{C}$ until further use.

\subsection{Preparation of cold onion alcohol extract}

Alcoholic extraction was performed by soaking $1 \mathrm{~kg}$ of fresh leaves in $10 \mathrm{~L}$ of $80 \%$ ethanol for $24 \mathrm{~h}$ and then refluxing for $2 \mathrm{~h}$. The alcoholic extract was frozen at $-80^{\circ} \mathrm{C}$ for $4 \mathrm{~h}$ and then mechanically lyophilized for $1 \mathrm{~h}$. The lyophilized material was ground into a powder and stored frozen at $-20^{\circ} \mathrm{C}$ until further use.

\subsection{Test grouping}

Three batches of male rats were used ( $\mathrm{n}=136)$. After a one-week adaptation period, the first batch of rats were randomly allocated to test the effect of the aqueous extract. The groups comprised a blank, positive control, model control, and three aqueous extract groups (high, medium, and low dose). The groups contained eight rats each. The second batch of rats was used to test the effect of the alcoholic extract. The groups comprised a blank, positive control, model control, and three alcohol extract groups (high, medium, and low dose). The groups contained eight rats each. Finally, the optimal dose for corpus cavernosum pathway activity was selected using a blank group, model group, three aqueous extract groups (as before), and three alcohol extract groups (as before), with eight rats per group.

\subsection{Establishment of rat model of kidney yang deficiency}

Except for the blank group, rats in each group were intramuscularly injected with hydrocortisone $(25 \mathrm{mg} / \mathrm{kg})$ once a day for 14 days. Beginning on day 5 of the regimen, intragastric administration was performed every morning.

\subsection{General observations}

From the start of administration, body weight, hair color change, defecation, hair loss, body temperature change, ear color change, activity status, and other aspects were observed and recorded every 3 days.

\subsection{Determination of sexual behavior parameters}

\section{Female preparation}

At $48 \mathrm{~h}$ before the formal test, $30 \mu \mathrm{g} /$ day of estradiol benzoate was injected subcutaneously, with progesterone $(50 \mu \mathrm{g})$ injected $4 \mathrm{~h}$ before the female was in estrus.

\section{Test method}

In the last week of the experiment, each group of male rats was randomly selected from 19:00 to 22:00 every night. Rats were transferred to a cage housing the same number of estrus female rats. Mating took place in a quiet laboratory environment. A camera was installed over the cage for recording. The sexual behavior parameters of each group of rats were counted, including the insertion latency (the time from the introduction of the female in the cage to the first insertion into the vagina), the number of riding cycles to ejaculation, and the number of vaginal insertions prior to ejaculation. 


\subsection{Determination of reproductive function}

\section{Organ coefficient of sexual organs}

The rats were weighed on the last day of the experiment. After anesthesia, blood was quickly collected and open surgery were performed to remove the bilateral kidney, testis, epididymis, prostate and seminal vesicles. The wet weight of each tissue was determined and recorded using a precision balance. The visceral organ coefficient (\%) was calculated as the organ mass divided by the body weight, with that multiplied by 100 . The testes of each group were weighed and placed in a $50 \mathrm{~mL}$ centrifuge tube containing $10 \%$ formalin.

\section{Detection of sperm motility and viability}

The bilateral epididymites of the test rats were weighed. The right epididymis tail was cut out and placed in a plate containing $5 \mathrm{~mL}$ of $0.9 \%$ sodium chloride solution. The tissue was cut and incubated in a $37^{\circ} \mathrm{C}$ water bath for $5 \mathrm{~min}$. The sperm was automatically swallowed, and $100 \mu \mathrm{L}$ of the supernatant was aspirated into a $1.5 \mathrm{~mL}$ centrifuge tube and diluted with three volumes of $0.9 \%$ saline. A drop of the dilute suspension was mixed on the slide. An automated computer-assisted sperm analyzer was used to observe sperm motility. The sperm mixture was tested for sperm viability and viability using scanning electron microscopy.

\section{Testicular sectioning and observation of microstructure}

The testes of the rats in the experimental group were collected, weighed, and fixed in 10\% formalin for 4 days. The soaked tissue was cut into $3 \times 2 \mathrm{~mm}$ pieces, dehydrated, and infused with paraffin using an embedding machine. The paraffinized tissues were sectioned ( $5 \mu \mathrm{m}$ in thickness). The sections were stained using hematoxylin and eosin (H\&E) stain and the microstructure of the testes was observed using an optical microscope.

\section{Determination of testosterone content in serum}

The heart was bled $24 \mathrm{~h}$ after the last gavage. The blood collection time was 9:00 am to 11:00 am. All rats were anesthetized with ether and immobilized in a rat fixation plate. Testosterone in serum was determined using a commercial kit following the manufacturer's instructions. The optical density (OD) was determined within $30 \mathrm{~min}$ at $450 \mathrm{~nm}$ following addition of a standard enzyme solution. The sample OD was compared to values generated in a standard curve. A regression equation of the standard curve was formulated. The OD value of the sample was substituted into the equation to calculate the corresponding sample. The concentration was then multiplied by the dilution factor to determine sample testosterone concentration.

\section{Determination of sex hormone content}

Serum corticotropin releasing hormone (CRH), luteinizing hormone $(\mathrm{LH})$, and gonadotropin releasing hormone $(\mathrm{GnRH})$ levels were measured by a double antibody sandwich method. The procedures for the for $\mathrm{LH}, \mathrm{GnRH}$, and CRH kits were essentially the same. Before the start of the experiment, blank, standard, and sample wells were placed in the 96-well plate.
All reagents and serum samples to be tested were shaken and equilibrated to room temperature. The kit loading steps are shown in Supplementary Table S3.

\subsection{Determination of serum superoxide dismutase (SOD) and malondialdehyde (MDA) activities}

SOD

SOD activity was determined using the SOD kit and protocol of the Nanjing Institute of Bioengineering. The main technical performance aspects of the kit were as follows: control $\mathrm{OD} \geq 0.2$, reaction temperature $37^{\circ} \mathrm{C}$, wavelength $450 \mathrm{~nm}$, intra-catch coefficient of variation (CV) $5.05 \%$, batch CV $3.32 \%$, and detection limit $0.5 \mathrm{U} / \mathrm{mL}$. The test operation is summarized in Supplementary Table S4. In the preliminary test, two sera of the normal group were randomly selected and diluted to different concentrations. A dilution ratio of 40 to $60 \%$ was selected and then a formal batch test was performed.

\section{$M D A$}

MDA content was determined by thiobarbituric acid colorimetry using the MDA kit of the Nanjing Institute of Bioengineering. The three standard reagents were configured and the procedure carried out as outlined in Supplementary Table S5.

\subsection{Determination of nitric oxide synthase (NOS) and cGMP in rat corpus cavernosum}

Under aseptic conditions, approximately $2 \mathrm{~mm}$ of corpus cavernosum tissue under the tunica albuginea root was removed and cut into six pieces with ophthalmic scissors. Penile tissue (50 mg) was obtained and added to $200 \mu \mathrm{L}$ of $0.9 \%$ physiological saline for mechanized homogenization. The homogenate was poured into a sterile tube containing $3 \mathrm{~mL}$ of physiological saline and centrifuged at $3000 \mathrm{rpm}$ for $5 \mathrm{~min}$. One milliliter of the supernatant was added to a $1.5 \mathrm{~mL}$ centrifuge tube and frozen at $-20^{\circ} \mathrm{C}$ until the time of testing. NOS and cGMP in rat corpus cavernosum were measured by ELISA kits in 96-well plates, which also included wells for blanks and standards. All reagents and serum samples to be tested were shaken and equilibrated to room temperature beforehand.

\subsection{Statistical analysis}

The experimental data were processed by SPSS (ver. 17.0) software. The data were statistically analyzed by the Duncan multiple comparison method. The results are expressed as mean \pm standard deviation $(\mathrm{x} \pm \mathrm{s})$. A $p$-value $<0.05$ was considered significant.

\section{Results}

\subsection{General conditions of rats}

In the rat model of kidney yang deficiency, appetite, consumption of drinking water, range of activity, and urine production was observed to have increased, and then decreased by day 8 of intramuscular injection of hydrocortisone. As the 
injection period was prolonged, there was a gradual appearance of slow weight gain, decreased body temperature, unresponsiveness, chills on the back of the bow, and body hair was sparse and exhibited a loss of luster.

\subsection{Effects of victory onion extract on sexual behavior in rats}

The effects of aqueous extract of victory onions on rat sexual behavior are shown in Table 1. Compared with the blank group, the insertion latency of the model group increased significantly, and the number of insertions and number of riding cycles decreased significantly, indicating that hydrocortisone decreased in mating ability in rats. The high dose of the cold onion extract significantly shortened the insertion latency compared with the model group. The number of insertions and the number of rides in the high dose and medium dose groups were significantly higher than those in the model group. Rats' sexual behavior was restored to normal by the high dose. The effects of ethanol extract of victory onions on sexual behavior in rats are shown in Table 1. Compared with the model group, the insertion latency, number of insertions, and number of rides were significantly less than or increased in addition to the number of rides in the low dose group. The insertion latency of the high dose group was significantly reduced compared with the positive group. The number of rides has increased significantly. The insertion latency, number of insertions, and number of rides in the high dose group were not significantly different from those in the blank group. The results indicated that in rats with kidney yang deficiency improved and promoted sexual behavior. The mating ability of the high dose group was restored to normal. The effect was slightly better than that of the positive control group orally administered Jingui Shenqi.

\subsection{Effect of extracts of victory onions on organ coefficient of reproductive organs}

\section{Effect of aqueous extract}

The results are summarized in Table 2. The organ coefficient of the reproductive organs in the model group of kidney dysfunction was significantly lower than that in the blank group, indicating that hydrocortisone caused shrinkage of the reproductive organs. The organ coefficient of the reproductive organs of the cold onion aqueous extract treatment group was significantly higher than that of the model group. The kidney coefficient and epididymis coefficient of the cold onion extract treatment group showed an increasing trend with the increase of the dose, but there was no significant difference between the treatments or compared with the positive control group.

Table 1. Effect of water and ethanol extracts from A. victorialis on sexual behavior in rats

\begin{tabular}{|c|c|c|c|c|c|c|}
\hline \multirow[b]{2}{*}{ Group } & \multicolumn{3}{|c|}{ Water Extract } & \multicolumn{3}{|c|}{ Ethanol Extract } \\
\hline & Insert latency (s) & $\begin{array}{l}\text { Number of } \\
\text { insertions }\end{array}$ & Number of riding & Insert latency $(\mathrm{s})$ & $\begin{array}{l}\text { Number of } \\
\text { insertions }\end{array}$ & Number of riding \\
\hline Blank & $157 \pm 19.64^{\mathrm{b}}$ & $18.00 \pm 2.53^{\mathrm{a}}$ & $22.83 \pm 1.47^{\mathrm{a}}$ & $141.83 \pm 21.38^{\mathrm{d}}$ & $12.5 \pm 2.88^{\mathrm{b}}$ & $32.83 \pm 7.11^{\mathrm{a}}$ \\
\hline Model group & $257.67 \pm 22.33^{\mathrm{a}}$ & $9.00 \pm 1.27^{\mathrm{d}}$ & $11.33 \pm 1.63^{\mathrm{b}}$ & $278.17 \pm 17.44^{\mathrm{a}}$ & $7.00 \pm 3.16^{c}$ & $21.33 \pm 2.25^{c}$ \\
\hline Positve group & $163.33 \pm 24.93^{b}$ & $14.00 \pm 2.00^{\mathrm{bc}}$ & $24 \pm 4.34^{\mathrm{a}}$ & $178.83 \pm 39.94^{c}$ & $18.17 \pm 4.31^{\mathrm{a}}$ & $24.5 \pm 2.81^{\mathrm{bc}}$ \\
\hline Low dose group & $242.83 \pm 14.93^{\mathrm{a}}$ & $11.67 \pm 1.63^{c}$ & $12.33 \pm 1.75^{\mathrm{b}}$ & $248.33 \pm 17.32^{\mathrm{b}}$ & $12.83 \pm 1.47^{\mathrm{b}}$ & $21.33 \pm 2.31^{c}$ \\
\hline Medium dose group & $251 \pm 24.75^{\mathrm{a}}$ & $13.00 \pm 1.41^{\mathrm{bc}}$ & $20.17 \pm 3.43^{\mathrm{a}}$ & $234 \pm 13.89^{\mathrm{b}}$ & $13.67 \pm 2.50^{\mathrm{b}}$ & $27.5 \pm 4.76^{\mathrm{b}}$ \\
\hline High dose group & $178.83 \pm 29.94^{\mathrm{b}}$ & $14.67 \pm 2.58^{\mathrm{b}}$ & $22.5 \pm 4.09^{\mathrm{a}}$ & $150.50 \pm 31.95^{\mathrm{d}}$ & $15.67 \pm 2.93^{\mathrm{ab}}$ & $35.5 \pm 5.01^{\mathrm{a}}$ \\
\hline
\end{tabular}

Note: Different lowercase letters represent significant differences between groups $(p<0.05)$.

Table 2. Effect of water and ethanol extracts from A. victorialis on organ coefficient of reproductive organs in rats (\%).

\begin{tabular}{|c|c|c|c|c|c|c|c|c|}
\hline \multirow[b]{2}{*}{ Group } & \multicolumn{4}{|c|}{ Water Extract } & \multicolumn{4}{|c|}{ Ethanol Extract } \\
\hline & $\begin{array}{l}\text { Renal organ } \\
\text { coefficient }\end{array}$ & $\begin{array}{c}\text { Epididymis } \\
\text { organ coefficient }\end{array}$ & $\begin{array}{l}\text { Testicular organ } \\
\text { coefficient }\end{array}$ & $\begin{array}{c}\text { Seminal } \\
\text { vesicle \& prostate } \\
\text { organ coefficient }\end{array}$ & $\begin{array}{c}\text { Renal organ } \\
\text { coefficient }\end{array}$ & $\begin{array}{c}\text { Epididymis } \\
\text { organ coefficient }\end{array}$ & $\begin{array}{l}\text { Testicular organ } \\
\text { coefficient }\end{array}$ & $\begin{array}{c}\text { Seminal } \\
\text { vesicle \& prostate } \\
\text { organ coefficient }\end{array}$ \\
\hline Blank & $0.756 \pm 0.0320^{\mathrm{a}}$ & $0.316 \pm 0.015^{\mathrm{a}}$ & $1.012 \pm 0.020^{\mathrm{b}}$ & $0.694 \pm 0.0108^{b}$ & $0.722 \pm 0.046^{\mathrm{a}}$ & $0.32 \pm 0.024^{\mathrm{ab}}$ & $0.93 \pm 0.077^{a}$ & $0.65 \pm 0.066^{\mathrm{a}}$ \\
\hline $\begin{array}{l}\text { Model } \\
\text { group }\end{array}$ & $0.598 \pm 0.0310^{c}$ & $0.271 \pm 0.012^{\mathrm{b}}$ & $0.851 \pm 0.0391^{\mathrm{d}}$ & $0.516 \pm 0.032^{\mathrm{d}}$ & $0.610 \pm 0.041^{\mathrm{b}}$ & $0.287 \pm 0.053^{c}$ & $0.76 \pm 0.067^{c}$ & $0.516 \pm 0.021^{\mathrm{b}}$ \\
\hline $\begin{array}{l}\text { Positve } \\
\text { group }\end{array}$ & $0.671 \pm 0.0183^{\mathrm{b}}$ & $0.308 \pm 0.025^{\mathrm{a}}$ & $0.935 \pm 0.072^{c}$ & $0.696 \pm 0.038^{\mathrm{b}}$ & $0.671 \pm 0.0183^{\mathrm{a}}$ & $0.308 \pm 0.025^{b c}$ & $0.935 \pm 0.072^{\mathrm{a}}$ & $0.696 \pm 0.038^{a}$ \\
\hline $\begin{array}{l}\text { Low dose } \\
\text { group }\end{array}$ & $0.649 \pm 0.0499^{b}$ & $0.321 \pm 0.037^{a}$ & $0.995 \pm 0.043^{b}$ & $0.603 \pm 0.029^{c}$ & $0.701 \pm 0.047^{\mathrm{a}}$ & $0.301 \pm 0.018^{c}$ & $0.83 \pm 0.101^{b c}$ & $0.637 \pm 0.043^{\mathrm{a}}$ \\
\hline $\begin{array}{l}\text { Medium } \\
\text { dose group }\end{array}$ & $0.663 \pm 0.0241^{b}$ & $0.328 \pm 0.030^{\mathrm{a}}$ & $1.012 \pm 0.044^{\mathrm{b}}$ & $0.622 \pm 0.049^{c}$ & $0.718 \pm 0.053^{\mathrm{a}}$ & $0.322 \pm 0.019^{\mathrm{abc}}$ & $0.88 \pm 0.037^{\mathrm{a}}$ & $0.630 \pm 0.077^{\mathrm{a}}$ \\
\hline $\begin{array}{l}\text { High dose } \\
\text { group }\end{array}$ & $0.670 \pm 0.0568^{\mathrm{b}}$ & $0.337 \pm 0.029^{\mathrm{a}}$ & $1.074 \pm 0.032^{\mathrm{a}}$ & $0.769 \pm 0.072^{\mathrm{a}}$ & $0.720 \pm 0.038^{\mathrm{a}}$ & $0.343 \pm 0.023^{\mathrm{a}}$ & $0.96 \pm 0.077^{a}$ & $0.672 \pm 0.049^{\mathrm{a}}$ \\
\hline
\end{tabular}

Note: Different lowercase letters represent significant differences between groups $(p<0.05)$. 


\section{Effect of ethanol extract}

The results are presented in Table 2. The kidney and seminal vesicle plus prostate organ coefficient of the cold onion alcohol extract treatment group were significantly higher than the model group. There was no significant difference compared with the positive group and the blank group or between the treatment groups. There was no significant difference in the testicular organ coefficient between the high dose group and the high dose group.

\subsection{Effects of extracts of victory onions on sperm motility and viability}

\section{Effect of aqueous extract on sperm motility A grade}

The ratio of the aqueous extract of victory onions to the sperm motility A grade of rats is shown in Figure 1a. The proportion of sperm motility A grade in the kidney yang deficiency model group was significantly lower than that in the blank group, indicating that hydrocortisone caused the sperm motility of rats to decrease. The proportion of sperm motility in the epididymis of the rats treated with the onion extract was significantly higher than that of the model group $(p<0.05)$. The sperm motility A grade of the cold onion extract treatment group was significantly higher than that of the positive group $(p<0.05)$. With increased intragastric dose, the proportion of sperm motility A grade increased, with the high dose and middle dose groups displaying significantly higher values than the low dose group (Figure $1 \mathrm{~b}$ ). The findings indicated that the aqueous extract of victory onions could improve the proportion of motile sperm in the epididymis of rats with kidney yang deficiency. The improvement of sperm motility was observed to be better in the high dose group than in the positive control group.

The ratio of the aqueous extract of victory onions to the sperm motility $A+B$ grade is shown in Figure 1c. The proportion of sperm motility $\mathrm{A}+\mathrm{B}$ in the epididymis of the cold aqueous extract treatment group increased, and was significant in the high dose group. Higher than the kidney yang deficiency model group, and the high dose group was significantly higher than the positive group, and there was no significant difference from the blank group. The findings indicated that the aqueous extract of victory onions could improve the sperm motility of rats with kidney yang deficiency. The high dose was superior than the positive group in improving sperm motility in the epididymis of rats with kidney yang deficiency, with recovery of motility to the normal level.

\section{Effect of aqueous extract on sperm motility}

The effect of aqueous extract of victory onions on sperm motility in rats is shown in Figure 1d. The sperm motility in a)

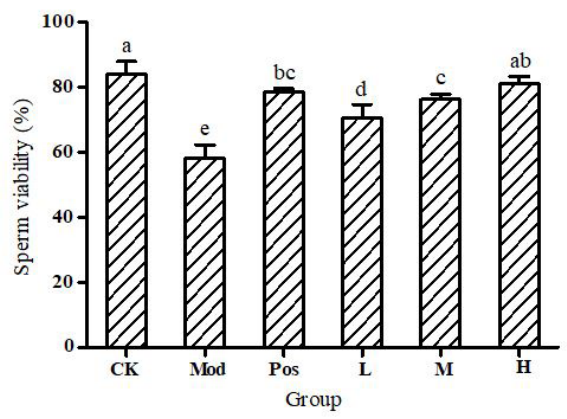

d)

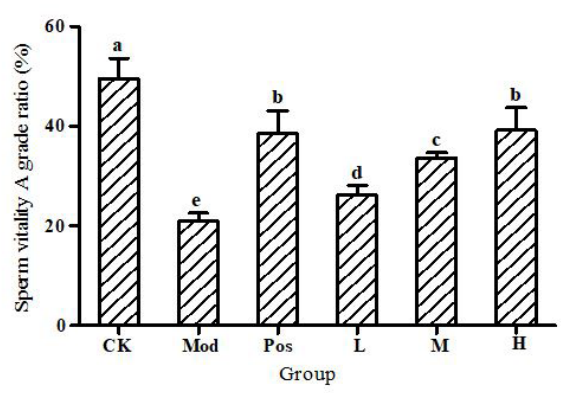

b)

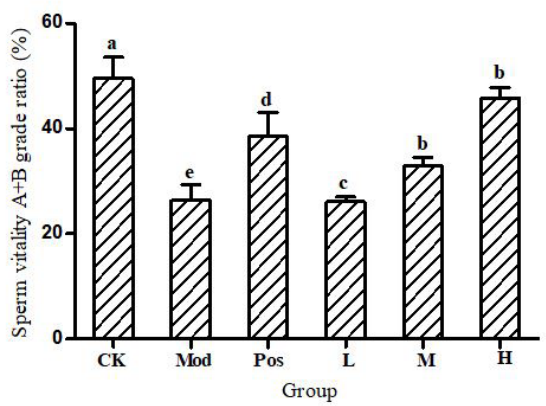

e)

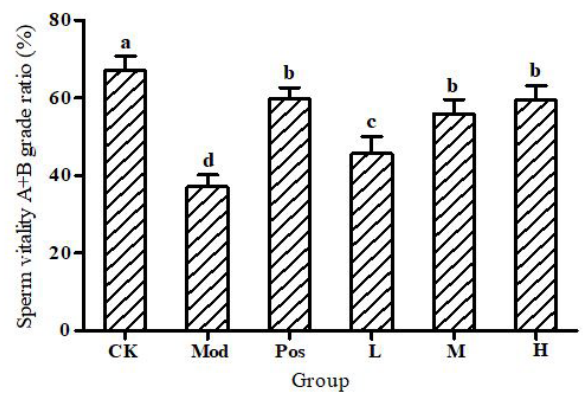

c)

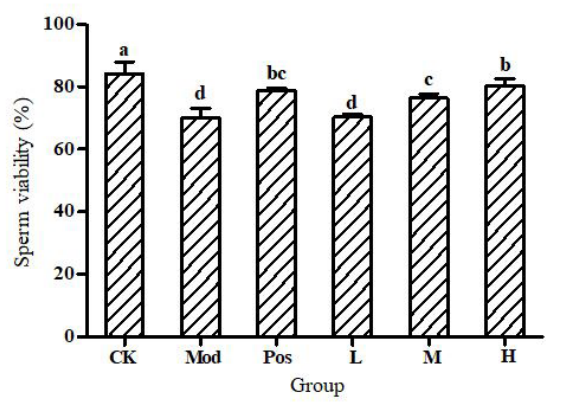

f)

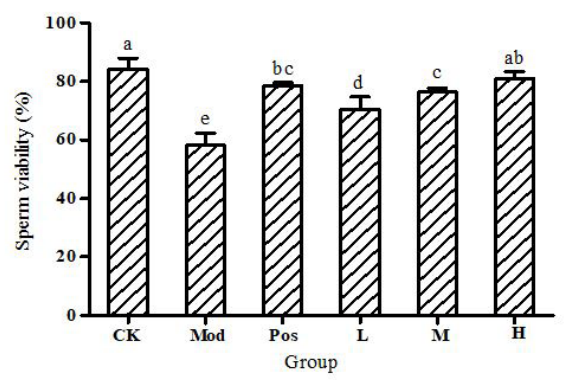

Figure 1. Effect of water extract from A. victorialis on A-grade motility of rat spermatozoa (a), on A and B grade motility of rats spermatozoa (b), on spermatozoa rate in rats (c), Effect of ethanol extract from Allium victorislis on spermatozoa motility (d), Effect of ethanol extract from A. victorialis on spermatozoa motility A and B in rats (e), Effect of ethanol extract from A. victorialis on spermatozoa rate in rats (f), [Datas are showed as the mean $\pm S D,(n=8)$. Different lowercase letters represent significant differences among groups $(p<0.05)]$. 
the epididymis of the middle and high dose groups of the cold onion extract treatment group was significantly higher than that of the model group. There was no significant difference compared with the positive group. These findings indicated that the aqueous extract could improve sperm motility. The increase in viability of the high dose group was equivalent to the positive control group.

\section{Effect of ethanol extract on sperm motility A grade}

The proportion of sperm extract of victory onion on sperm motility A grade is shown in Figure 1e. The effect of cold squid alcohol extract was also significantly higher than that of model group $(p<0.05)$. The sperm motility grade A was not significantly different between the high dose and positive groups $(p>0.05)$. The findings indicated that the ethanol extract of victory onions could improve the sperm A grade of the rats with kidney yang deficiency, with recovery to normal levels produced by the high dose.

\section{Effect of ethanol extract on sperm motility $A+B$ level}

The effect of ethanol extract of victory onions on sperm motility $A+B$ grade is shown in Figure 1f. The proportion of sperm motility $\mathrm{A}+\mathrm{B}$ in the alcohol extract group was significantly higher than that in the model group, and there was no significant difference between the middle and high dose groups and the positive group. These observations indicated that the effect of increased sperm motility $A+B$ level in the high dose group was consistent with the effect of the orally administered Jingui Shenqi. Alfalfa alcohol extract can also increase the proportion of sperm motility $\mathrm{A}+\mathrm{B}$.

\section{Effect of ethanol extract of cold onion on sperm motility}

As shown in Figure 1f, the sperm motility of the rats increased with increasing dose of the cold stalk extract, and there was no significant difference between the groups. The sperm motility of the cold stalk extract treatment group was significantly higher than that of the model group. The sperm motility of the blank group was significantly higher than that of the model group $(p<0.05)$. The spermatozoa of the victory onions, the high dose group, and the positive drug were administered. There was no significant difference in the survival rate $(p>0.05)$. There was no significant difference in sperm motility between the high dose and blank control groups. The findings indicated that the ethanol extract of victory onions can also improve the sperm motility of rats with kidney yang deficiency. Comparison with the blank control group revealed that the sperm motility of the high dose group was close to the normal group Kidney dysfunction.

\subsection{Effects of extracts of victory onions on serum testosterone levels}

\section{Effect of aqueous extract}

The results are shown in Table 3. The testosterone content in the serum of the cold onion extract treatment group was 138.387 to $146.383 \mathrm{pg} / \mathrm{mL}$, which was significantly higher than that of the kidney yang deficiency model group (114.862 pg/mL). Testosterone levels in rat serum did not differ significantly between the middle and high dose groups and the positive group, while the testosterone content in the blank group was $161.640 \mathrm{pg} / \mathrm{mL}$. The effect of increasing the testosterone content in the serum in rats with kidney yang deficiency equivalent to the effect of positive drug treatment.

\section{Effect of ethanol extract}

The results are shown in Table 3. The testosterone content in the serum of the cold-sucking alcohol extract treatment group was significantly higher than that of the model group of $115.66 \mathrm{pg} / \mathrm{mL}$. The testosterone content of the middle dose group was $145.266 \mathrm{pg} / \mathrm{mL}$, which was similar to the testosterone content of the positive and blank groups. The testosterone level in the high dose group was $159.034 \mathrm{pg} / \mathrm{mL}$, which was significantly higher than that in the positive and the blank groups. The medium dose and high dose melamine alcohol extract treatment group of male rats with kidney yang deficiency displayed normal serum testosterone levels Kidney dysfunction Kidney dysfunction.

\subsection{Effect of extracts of victory onion on rat testicular morphology}

\section{Effect of aqueous extract}

The results are shown in Figure 2(A-F). Optical microscopy of $\mathrm{H} \& \mathrm{E}$ stained sections at $100 \times$ magnification revealed tissue size and morphology. Neat arrangement of the seminiferous tubules was evident, as were spermatogonia and spermatocytes at different developmental stages, sperm cells and sperm. Spermatogenic epithelial cells were well-distributed, interstitial cells were abundant, and cell structure was well-defined (Figure 2A). Compared with the normal group, the cell tissue of the model group (Figure 2C) displayed an irregular shape, uneven distribution, disordered arrangement of seminiferous tubules, partial cell detachment in the lumen, thinning of spermatogenic epithelial cells, and decreased sperm count. In rats with kidney yang deficiency, the damage to testicular cells was improved with treatment using onion aqueous extract. The effect of aqueous extract was pronounced on testicular spermatogenic epithelial cells (Figure 2D). In the middle dose group, the tissues and seminiferous tubules were

Table 3. Effects of water and ethanol extracts from A. victorialis on serum testosterone content in rats.

\begin{tabular}{lccc}
\hline \multirow{1}{*}{ Group } & \multicolumn{1}{c}{ Water Extract } & & Ethanol Extract \\
\cline { 2 - 2 } & $\begin{array}{c}\text { Testosterone content } \\
(\mathrm{pg} / \mathrm{mL})\end{array}$ & & $\begin{array}{c}\text { Testosterone content } \\
(\mathrm{pg} / \mathrm{mL})\end{array}$ \\
\hline Blank & $161.640 \pm 3.340^{\mathrm{a}}$ & & $146.066 \pm 5.516^{\mathrm{b}}$ \\
Model group & $114.862 \pm 5.000^{\mathrm{d}}$ & & $115.660 \pm 2.395^{\mathrm{d}}$ \\
Positve group & $147.957 \pm 5.853^{\mathrm{b}}$ & & $147.957 \pm 5.853^{\mathrm{b}}$ \\
Low dose group & $138.387 \pm 2.053^{\mathrm{c}}$ & & $134.183 \pm 4.970^{\mathrm{c}}$ \\
Medium dose group & $146.066 \pm 5.516^{\mathrm{b}}$ & & $145.266 \pm 2.643^{\mathrm{b}}$ \\
High dose group & $147.353 \pm 2.517^{\mathrm{b}}$ & & $159.034 \pm 3.560^{\mathrm{a}}$ \\
\hline
\end{tabular}

Note: Different lowercase letters represent significant differences between groups $(p<0.05)$ 
arranged neatly, and the numbers of spermatozoa and interstitial cells in the cavity were increased (Figure 2E). In the low dose group, the tissue arrangement was disordered, the number of sperm in the cavity was greater than that in the model group, and there was no cell shedding (Figure 2F). Compared with the positive control group (Figure $2 \mathrm{~B}$ ), the high dose group displayed an increased number of stromal cells. The findings indicated that the onion aqueous extract improved testicular tissue of rats with kidney yang deficiency, especially in the middle and high dose groups.

\section{Effect of ethanol extract}

The results are shown in Figure 2(G-L). The testicular tissue changes in the ethanol extract group after $\mathrm{H} \& \mathrm{E}$ staining were observed by optical microscopy at $100 \times$ magnification. The testicular cell tissue of the kidney dysfunction model group (Figure 2G) was irregular in shape compared with the normal group (Figure $2 \mathrm{H}$ ). Compared with the positive group, the rats orally administered Jingui Shenqi and the cold-sucking alcohol extract had a relatively uniform dose and high dose tissue arrangement, the levels were relatively clear, and the intercellular substance was abundant. Primary cells, sperm cells, sperm, etc. Intraluminal sperm in the low dose group were relatively less than the normal group, but the tissue structure was improved compared with the model group, and no exfoliated cells were observed. The observations can explain the effect of hydrocortisone-induced kidney yang deficiency on the testicular tissue damage after treatment with the onion ethanol extract.

\subsection{Effects of extracts of victory onion on sex hormones}

\section{Effect of aqueous extract}

The results are shown in Table 4. Serum CRH, GnRH, and LH levels in the kidney dysfunction model group were not significantly different from those in the blank group, indicating that hydrocortisone caused a hormone endocrine disorder in the HPG of the rats. After the succulent aqueous extract was
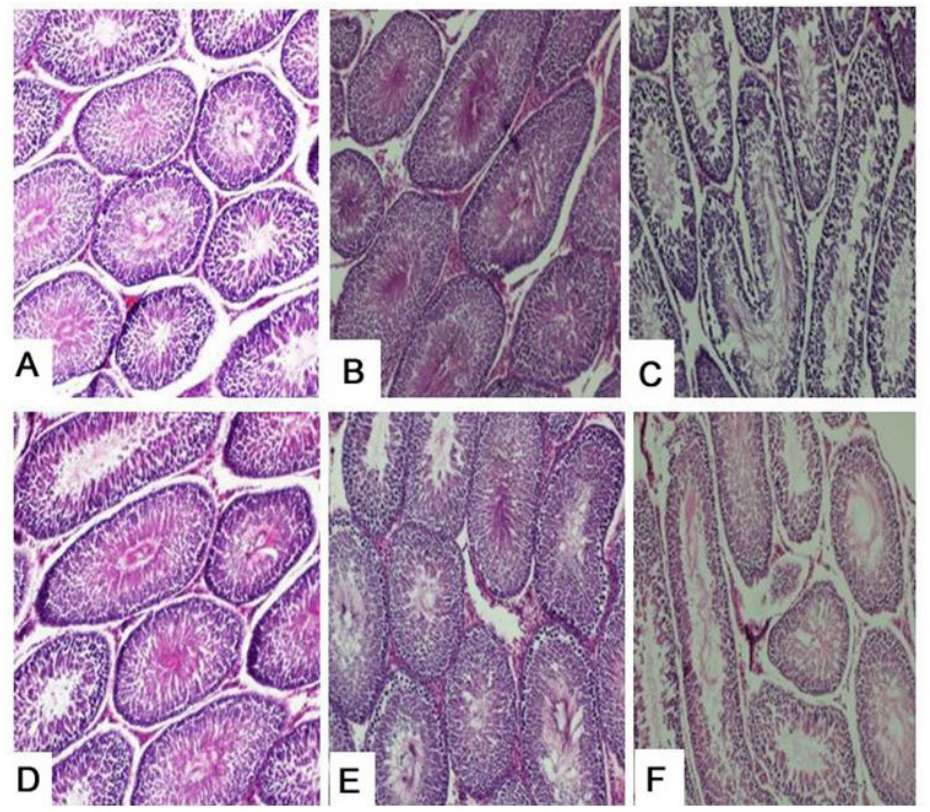

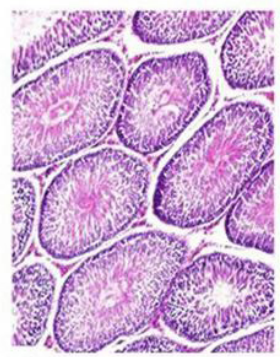

G

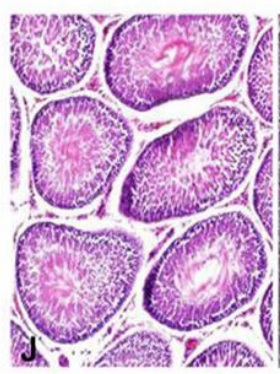

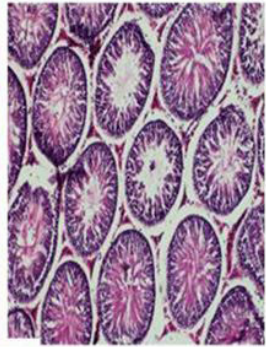

$\mathrm{H}$

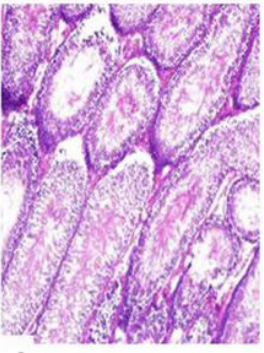

I
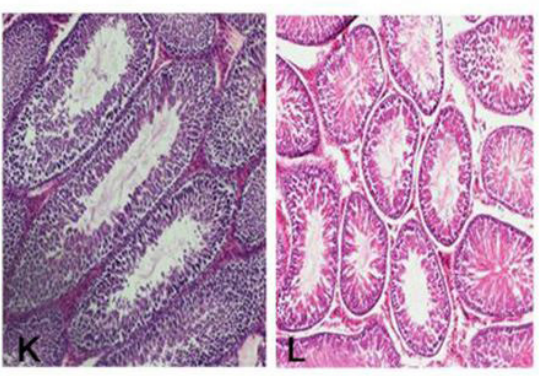

Figure 2. Effect of water extract from A. victorialis on testicular tissue in rats HE staining $100 \times$ (A: Control group B: Positive group C:Model group D: Water high dose group E: Water extraction medium dose group F: Water extraction low dose group); Effect of ethanol extract from $A$. victorialis on testicular tissue in rats (HE staining $\times 100)(\mathrm{G}$ : Control group H: Positive group I:Model group J: Ethanol high dose group K: Ethanol extraction medium dose group L: Ethanol extraction low dose group).

Table 4. Effects of water and ethanol extracts from A. victorialis on serum sex hormones in rats.

\begin{tabular}{lcccccccc}
\hline \multirow{2}{*}{ Group } & \multicolumn{3}{c}{ Water Extract } & & \multicolumn{3}{c}{ Ethanol Extract } \\
\cline { 2 - 3 } & CRH $(\mathrm{U} / \mathrm{mL})$ & $\mathrm{LH}(\mathrm{U} / \mathrm{mL})$ & $\mathrm{GnRH}(\mathrm{U} / \mathrm{mL})$ & & $\mathrm{CRH}(\mathrm{U} / \mathrm{mL})$ & $\mathrm{LH}(\mathrm{U} / \mathrm{mL})$ & $\mathrm{GnRH}(\mathrm{U} / \mathrm{mL})$ \\
\hline Blank & $101.305 \pm 0.750^{\mathrm{a}}$ & $26.641 \pm 6.175^{\mathrm{d}}$ & $38.319 \pm 4.733^{\mathrm{a}}$ & & $82.695 \pm 6.323^{\mathrm{a}}$ & $63.527 \pm 7.490^{\mathrm{d}}$ & $40.128 \pm 8.4629^{\mathrm{a}}$ \\
Model group & $67.090 \pm 6.434^{\mathrm{c}}$ & $44.093 \pm 2.491^{\mathrm{a}}$ & $17.970 \pm 1.104^{\mathrm{d}}$ & & $57.596 \pm 1.875^{\mathrm{c}}$ & $109.183 \pm 2.986^{\mathrm{a}}$ & $7.293 \pm 1.636^{\mathrm{d}}$ \\
Positve group & $83.824 \pm 7.477^{\mathrm{b}}$ & $29.324 \pm 3.691^{\mathrm{d}}$ & $29.420 \pm 2.969^{\mathrm{b}}$ & & $83.824 \pm 7.477^{\mathrm{a}}$ & $72.922 \pm 7.422^{\mathrm{c}}$ & $38.319 \pm 4.733^{\mathrm{a}}$ \\
Low dose group & $84.870 \pm 3.554^{\mathrm{b}}$ & $36.475 \pm 5.271^{\mathrm{bc}}$ & $19.613 \pm 2.125^{\mathrm{d}}$ & & $73.167 \pm 5.434^{\mathrm{b}}$ & $83.264 \pm 5.662^{\mathrm{b}}$ & $15.792 \pm 2.525^{\mathrm{c}}$ \\
Medium dose group & $89.998 \pm 2.020^{\mathrm{b}}$ & $37.202 \pm 3.185^{\mathrm{b}}$ & $25.058 \pm 4.773^{\mathrm{c}}$ & & $74.993 \pm 2.630^{\mathrm{b}}$ & & $83.402 \pm 6.232^{\mathrm{b}}$ & $14.243 \pm 0.996^{\mathrm{c}}$ \\
High dose group & $96.575 \pm 0.734^{\mathrm{a}}$ & $30.727 \pm 2.631^{\mathrm{dc}}$ & $28.287 \pm 8.996^{\mathrm{b}}$ & & $77.251 \pm 8.131^{\mathrm{ab}}$ & & $74.492 \pm 6.906^{\mathrm{c}}$ & $25.366 \pm 2.190^{\mathrm{b}}$ \\
\hline
\end{tabular}

Different lowercase letters represent significant differences between groups ( $p<0.05)$; $\mathrm{CRH}$ : corticotropin releasing hormone; LH: luteinizing hormone; GnRH: Gonadotropin-releasing hormone. 
administered to rats with kidney yang deficiency, the content of $\mathrm{CRH}, \mathrm{GnRH}$, and LH in other treatment groups was significantly higher than that in the model group, except that the GnRH content in the low dose group was not significantly different from that in the model group. With the increase of the dose of the onion aqueous extract, the serum $\mathrm{CRH}$ content increased gradually. The CRH content in the low and middle dose groups was not significantly different from the positive control group, but the high dose group was significantly higher than the positive group. The content reached the blank group level $(96.575 \mathrm{U} / \mathrm{mL})$. The serum LH content of the rats with kidney yang deficiency in the low and medium dose onion aqueous extract groups was significantly higher than that in the positive and blank control groups. The value in the high dose group was slightly higher, but not significantly differ, than the positive and blank groups. With the increase of the onion aqueous extract dose, serum GnRH content also increased, with a significant difference between the different dose groups. The high dose value of $28.287 \mathrm{U} / \mathrm{mL}$ was close to the value of the positive control group $(29.420 \mathrm{U} / \mathrm{mL})$. The findings indicated that the aqueous extract of cold onion regulated the hormone endocrine function of the HPG in rats with kidney dysfunction. In these rats with kidney yang deficiency high dose aqueous extract restored the normal levels of $\mathrm{CRH}$, $\mathrm{LH}$, and the secretion of GnRH.

\section{Effect of ethanol extract}

The results are Kidney dysfunction shown in Table 4 . The effect of ethanol extract of victory onions on serum serotonin in rats with kidney yang deficiency similar to that of aqueous extract. There was no significant difference in CRH content between different doses of cold ethanol extract, which included the high dose, positive, and blank groups. The LH content in the high dose group was significantly lower than the medium and low dose groups, significantly higher than the blank group, and was not significantly different from the positive group. The GnRH content in the high dose group was significantly higher than that in the middle and low dose groups, but was significantly lower than the positive and blank groups. The findings indicated the ethanol extract of cold onion regulated endocrine level of the HPG axis of rats with kidney yang deficiency and that the regulation mediated by the high dose was superior than that of the middle and low dose groups.

\subsection{Effects of extracts of victory onion on serum SOD activity and MDA content}

\section{Effect of aqueous extract on serum MDA content}

MDA is the end product of cell membrane lipid peroxidation and is an important indicator of the severity of free radical attack. The effect of aqueous extract of victory onions on the MDA content in rat serum is presented in Table 5. The serum MDA content in the kidney yang deficiency model group was $9.298 \mathrm{nmol} / \mathrm{mL}$, which was significantly higher than the $4.012 \mathrm{nmol} / \mathrm{mL}$ in the blank control group, indicating that hydrocortisone caused the accumulation of damaging oxidative factors in rats. After the squid aqueous extract was administered, the MDA accumulation in the serum of rats with kidney yang deficiency was significantly reduced, and decreased further with increasing dose of the aqueous extract. The MDA content in the serum rats treated with the aqueous extract was slightly, but not significantly, higher than that of the positive group, which was $4.845 \mathrm{nmol} / \mathrm{mL}$. The MDA content of the high dose group was $4.243 \mathrm{nmol} / \mathrm{mL}$, which slightly higher than the blank group, with no significant difference between them. The findings indicated that the onion aqueous extract has an antioxidant role in the rat body. Oxidative damage is reduced and, for the high dose, substantially ameliorated.

\section{Effect of ethanol extract on serum MDA content}

The results are presented in Table 5. The content of MDA in the serum of the cold ethanol extract treatment group was significantly lower than that of the model group. The MDA content of the middle- and low dose groups ( 4.121 and $4.532 \mathrm{nmol} / \mathrm{mL}$, respectively) was basically the same as that of the positive group. The MDA content of the dose group was $3.722 \mathrm{nmol} / \mathrm{mL}$, which was not significantly different from the blank group. The findings indicated that the cold ethanol extract also has a beneficial antioxidant effect in rats and that the high dose treatment minimizes oxidative damage.

\section{Effect of aqueous extract on serum SOD activity}

The effect of aqueous extract of victory onions on SOD activity in serum of rats with kidney yang deficiency is presented in Table 5. SOD activities in Kidney dysfunction treated with low,

Table 5. Effect of water and ethanol extracts from A. victorialis on the content of MDA in serum of rats.

\begin{tabular}{lccccc}
\hline \multirow{2}{*}{ Group } & \multicolumn{2}{c}{ Water Extract } & & \multicolumn{2}{c}{ Ethanol Extract } \\
\cline { 2 - 3 } \cline { 5 - 6 } Blank & MDA $(\mathrm{nmol} / \mathrm{mL})$ & SOD vitality $(\mathrm{U} / \mathrm{mL})$ & & MDA $(\mathrm{nmol} / \mathrm{mL})$ & SOD vitality $(\mathrm{U} / \mathrm{mL})$ \\
Model group & $4.012 \pm 0.626^{\mathrm{d}}$ & $124.415 \pm 3.968^{\mathrm{a}}$ & & $3.790 \pm 0.505^{\mathrm{c}}$ & $151.486 \pm 6.398^{\mathrm{a}}$ \\
Positve group & $9.298 \pm 0.626^{\mathrm{a}}$ & $84.309 \pm 3.169^{\mathrm{d}}$ & & $5.445 \pm 0.312^{\mathrm{a}}$ & $107.994 \pm 8.957^{\mathrm{d}}$ \\
Low dose group & $4.432 \pm 0.142^{\mathrm{cd}}$ & $128.697 \pm 4.511^{\mathrm{a}}$ & & $4.432 \pm 0.142^{\mathrm{b}}$ & $128.697 \pm 4.511^{\mathrm{c}}$ \\
Medium dose group & $5.655 \pm 0.283^{\mathrm{b}}$ & $92.872 \pm 4.973^{\mathrm{c}}$ & & $4.532 \pm 0.464^{\mathrm{b}}$ & $126.522 \pm 2.318^{\mathrm{c}}$ \\
High dose group & $4.845 \pm 0.387^{\mathrm{c}}$ & $104.202 \pm 1.780^{\mathrm{c}}$ & & $4.121 \pm 0508^{\mathrm{bc}}$ & $126.869 \pm 3.645^{\mathrm{c}}$ \\
\hline
\end{tabular}

Different lowercase letters represent significant differences between groups $(p<0.05)$. 
medium, and high doses of victory onions aqueous extract were $92.872,104.202$, and $115.660 \mathrm{nmol} / \mathrm{mL}$, respectively, which were significantly larger than the value in the model group. The SOD activity of the high dose group was significantly greater than that of the middle- and low dose groups, but did not reach the levels of the positive group $(128.697 \mathrm{nmol} / \mathrm{mL})$ and the blank group $(124.415 \mathrm{nmol} / \mathrm{mL})$. The findings indicated that the aqueous extract of victory onions had the ability to enhance the antioxidant capacity in rats with kidney yang deficiency, but the SOD activity was not as good as that produced by the oral administration of Jingui Shenqi.

\section{Effect of ethanol extract on SOD activity}

The results are shown in Table 5. The SOD activity in the serum of the cold ethanol extract treatment group was significantly higher than that of the model group $(107.994 \mathrm{nmol} / \mathrm{mL})$ and the low and medium dose alcohol extracts (126.522 and $126.869 \mathrm{nmol} / \mathrm{mL}$, respectively). Similar to the SOD activity of the positive group, the SOD activity of the high dose group was $140.883 \mathrm{nmol} / \mathrm{mL}$, which was significantly higher than that of the positive group. The findings indicated that the ethanol extract of victory onions improved the SOD activity in the serum of rats with kidney dysfunction and that the effect was equivalent to the positive control group.

\section{Discussion}

Modern medical research on animal models of sexual dysfunction has increased and many animal models have been developed. Based on prior research, this study used hydrocortisone intramuscular injection to establish kidney yang deficiency. This hydrocortisone-based rat model is one of the commonly used methods to model kidney yang deficiency. A previous study used the model to examine serum testosterone, GnRH, and CRH (Lu et al., 2011). The level of hormones decreased and testicular damage occurred, which eventually led to abnormal spermatogenic function and decreased sperm count. In the present study, the rats displayed decreased appetite, increased water intake and urine output, and decreased activity. With a prolonged period of injection, body weight gradually increased, body temperature decreased, the reaction was slow, the back of the bow was chilly, and body hair became sparse and lacked the usual gloss (Sumalatha \& Kumar, 2010).

The number of riding times and number of insertions of the male rats were recorded. Both parameters are indicators of strong sexual desire. The assessment of mating behavior revealed that the high dose of both the onion aqueous and ethanol extracts significantly increased the number of captures and rides, and significantly shortened the rides. Insertion latency, indicating the mating ability of kidney yang deficiency rats, was improved by the onion extract. Coincidentally, sexual desire was promoted.

Hydrocortisone induction can cause androgen disorder in rats and can affect the weight of the sexual organs. Animal accessory gland organ is a commonly used method to detect reproductive dysfunction. The testis is the most important sexual organ of male animals. It produces sperm and is the main secretory organ of androgen, which is important role in maintaining male normal reproductive function. The epididymis promotes sperm development and maturation, and is important in sperm storage and transport (Alzweri \& Burnett, 2018). The seminal vesicle is one of the most important secretory glands in the reproductive system. The sperm is produced from the seminiferous tubules of the testis, but lacks the ability to move. Continued maturation in the epididymis is necessary, and the energy for the extracorporeal movement of sperm must be provided by the seminal vesicle. Coagulation proteins secreted by the seminal vesicles and prostaglandin substances are important for normal fertilization. Testosterone is a male gonadotropin produced by Leydig cells (Zhang et al., 2018)

Our results indicate the reproductive function of rats with kidney yang deficiency could be improved by improving the weight of the genital organs Kidney dysfunction Kidney dysfunction. The density, vigor, and viability of sperm are direct indicators of the quality of semen in male animals, and are closely related to normal reproductive function. We observed that the injection of hydrocortisone resulted in varying extents of atrophy of the testis, epididymis, seminal vesicle, and prostate of rats. Sperm develops in the epididymis, and the strength of exercise may be related to the secretion of prostate and seminal vesicle. Higher doses of the aqueous and ethanol extracts increased the weights of the seminal vesicle and prostate, and prostate and seminal vesicle secretions, resulting in increased motility of sperm. Increased testosterone content also results in the increased viability and motility of sperm. We observed that both the aqueous and ethanol extracts of onion improved sperm motility A grade, $\mathrm{A}+\mathrm{B}$ grade, and sperm motility. These effects were the same as produced by the oral administration of Wuzi Yanzong. Improvements in the quality of semen and reproductive function were evident.

The HPA regulates the spermatogenic function of the testis. The hypothalamus secretes $\mathrm{GnRH}$ to act on the pituitary gland to secrete FSH and LH. FSH and LH receptors are localized in the Leydig cell membrane. Binding of $\mathrm{LH}$ to its receptor promotes phosphorylation of Leydig cells and the conversion of cholesterol to pregnenolone to enhance testosterone synthesis. The observations of decreased levels of $\mathrm{CRH}, \mathrm{T}$, and $\mathrm{GnRH}$ and increased LH content in rats with kidney yang deficiency indicated the impairment of HPA axis. A consequence of the resulting weak negative feedback was the excess secretion of $\mathrm{LH}$. Compared with the model group, the CRH and GnRH levels were significantly increased (both $p<0.05$ ). in rats treated with either aqueous or ethanol extract, while the LH content was effectively inhibited These findings support the view that the onion extract can improve the reproductive endocrine in rats with kidney yang deficiency. The introduction of hydrocortisone can impair immune function, reduce antioxidant capacity, and led to the accumulation of free radicals. Consistent with these consequences, we observed an increase in the oxidative damage factor MDA and decrease in the antioxidant damage factor SOD in the model group. In comparison, these alterations were much less in rats treated with aqueous extract of onion, indicating that the kidney yang deficiency was improved. 
Kidney yang deficiency can cause penile erectile dysfunction. Penile erection normally results from the release of NO by NOS. The released NO activates cGMP, which in turn decreases intracellular calcium concentration, relaxes smooth muscle, and increases penile blood flow. These events induce erection. cGMP is inactivated by hydrolysis of phosphodithioate V. NOS is an important enzyme in the NO/cGMP signaling pathway in penile erection. The expression and activity of NOS depends on normal androgen levels in the body. An increase in testosterone levels leads to increased activity of NOS, and the release of NO increases the level of cGMP. The present results were consistent with this mechanism. Compared with the model group, NOS activity in the rat corpus cavernosum and the cGMP level were significantly increased (both $p<0.05$ ). Therefore, both the aqueous and ethanol extracts promoted penile erection, increased the number of mating insertions, and thus improve the mating ability. Onions are enriched in sterols, flavonoids, phenols, saponins, alkaloids, and sulfur-containing compounds. The observed improvement of sexual function in rats resulting from treatment with onion extract in rats may involve active substances, such as flavonoids, saponins, alkaloids, and the like. Further studies could seek to precisely clarify the compounds that are responsible as well as refining the mechanism of onion extract-mediated improvement in reproductive function.

\section{Conclusions}

This study was undertaken to improve edible value of A. victorialis and provide a theoretical basis for its further development and utilization. Thus, the protective effect of the A. victorialis extract on reproductive system injury in male rats was investigated. The aqueous and ethanol extracts of $A$. victorialis were obtained by reflux extraction. A model of kidney yang deficiency was established by injecting hydrocortisone into male SD rats. The experiment was conducted on rats divided into groups of 8 rats each: the blank group, Kidney dysfunction deficiency model group, the Jingui Shenqi pill positive control group, and the A. victorialis aqueous and ethanol extract groups (high, middle, and low dose groups $(1000 \mathrm{mg} / \mathrm{kg}, 800 \mathrm{mg} / \mathrm{kg}$, $400 \mathrm{mg} / \mathrm{kg}$ )). From the 5 th day after the model was established, the rats were administrated with the corresponding dose of A. victorialis extract and positive control drug every morning for 28 days. The changes of body weight, color, and activity of the rats were observed during the course of the study. Defecation and limb temperature were used to determine whether the model was successful or not. At the same time, the sexual behavior of the male rats was observed, and the visceral coefficients of the kidney, epididymis, testis, seminal vesicle, and prostate were calculated after gastric perfusion. The content of luteinizing hormone $(\mathrm{LH})$, gonadotropin releasing hormone $(\mathrm{GnRH})$, adrenocorticotropic hormone releasing hormone (CRH), testosterone, malondialdehyde (MDA), and the activity of superoxide dismutase (SOD) were measured in the serum. The morphological changes in the testes were observed by H\&E staining, the sperm motility and motility in the epididymis were analyzed, and monooxygenation in the rat corpus cavernosum was determined by evaluating the nitric oxide synthase (NOS) activity and cyclic guanosine monophosphate (cGMP) content.
The content of CRH, GnRH, and LH in serum of rats were significantly higher or lower than those of the model group. The CRH content in the high dose group was significantly higher than that in the positive group. The LH content in serum of rats with kidney yang deficiency was significantly higher than that of the positive group and blank control group. The content of $\mathrm{GnRH}$ in the serum of rats increased with the increase of aqueous extract dose, and there was significant difference between different dose groups. The effect trend of the ethanol extract of $A$. victorialis on the sex hormones in the serum of rats with kidney yang deficiency was similar to that of the aqueous extract. Compared with the model group, the serum MDA content in the A. victorialis aqueous extract group decreased significantly $(p<0.05)$, and the MDA content in the high dose group was significantly different from that in the blank group $(p>0.05)$. The content of MDA in the serum of rats treated with the ethanol extract was significantly lower than that of the model group. The content of MDA in the middle and low dose groups was basically the same as that in the positive group, but there was no significant difference between the two groups. The serum SOD activity of rats with kidney yang deficiency treated with the aqueous extract was significantly higher than that of the model group, and the SOD activity in the high dose group was significantly higher than that in the middle and low dose groups $(p<0.05)$. The serum SOD activity of the rats in the ethanol extract group was significantly higher than that in the model group, and the SOD activity in the high dose group was significantly higher than that in the middle and low dose groups and the positive group $(p<0.05)$. The activity of NOS and the content of cGMP in the rat corpus cavernosum with kidney yang deficiency were increased and improved after administration of $A$. victorialis extract. There was no significant difference in the activity of NOS between the high dose group of aqueous extract and the high dose group of ethanol extract. The cGMP content in the high dose group was significantly higher than that in the high dose group, but both values were lower than that in the positive group. From the above results, it can be concluded that the extract of $A$. victorialis can improve the semen quality, promote sexual behavior, increase the weight of organs of reproductive organs, and enhance the antioxidant function of the body in rats with deficiency of kidney yang. The extract was also observed to increase the expression of NOS and the content of cGMP in the corpus cavernosum of the penis and induce the erection of testes, both of which can improve mating ability. Thus, we can conclude that $A$. victorialis could have the potential to be developed into a functional food with positive effects.

\section{Acknowledgements}

This work was supported by Key Scientific and Technological Projects in Jilin Province (20160204029NY).

\section{References}

Alzweri, L., \& Burnett, A. L. (2018). Components of erection and ejaculation as the potential target systems for environmental toxicants. In S. C. Sikka \& W. J.G. Hellstrom. Bioenvironmental issues affecting men's reproductive and sexual health (pp. 391-400). Academic Press. http://dx.doi.org/10.1016/B978-0-12-801299-4.00024-4. 
Choi, J., Lee, K. T., Kim, W. B., Park, K. K., Chung, W. Y., Lee, J. H., Lim, S.-C., Jung, H.-J., \& Park, H.-J. (2005). Effect of Allium victorialis var. platyphyllum leaves on triton WR-1339-induced and poloxamer407-induced hyperlipidemic rats and on diet-induced obesity rats. Korean Journal of Pharmacognosy, 36(2), 109-115.

Corradi, P. F., Corradi, R. B., \& Greene, L. W. (2016). Physiology of the hypothalamic pituitary gonadal axis in the male. Urologic Clinics, 43(2), 151-162. http://dx.doi.org/10.1016/j.ucl.2016.01.001. PMid:27132572.

Ji, B., Li, Y. Y., Yang, W. J., Zhang, L. Z., Fang, M. S., Fu, H. Y., \& Shou, Q. Y. (2018). Jinkui Shenqi pills ameliorate asthma with "kidney yang deficiency" by enhancing the function of the hypothalamicpituitary-adrenal axis to regulate Thelper $1 / 2$ imbalance. EvidenceBased Complementary and Alternative Medicine, 2018, 1-6. http:// dx.doi.org/10.1155/2018/7253240. PMid:29576798.

Khan, S., Fatima, I., Kazmi, M. H., \& Malik, A. (2015). A new steroidal alkaloid from Allium victorialis. Chemistry of Natural Compounds, 51(6), 1134-1137. http://dx.doi.org/10.1007/s10600-015-1509-z.

Lee, E. (2014). Anti-inflammatory effects of A. victorialis extract in lipopolysaccharide exposed rats and raw 264.7 cells. Korean Journal Plant Research, 27(6), 707-713. http://dx.doi.org/10.7732/ kjpr.2014.27.6.707.

Lee, K. T., Choi, J. H., Kim, D. H., Son, K. H., Kim, W. B., Kwon, S. H., \& Park, H. J. (2001). Constituents and the antitumor principle of Allium victorialis var. platyphyllum. Archives of Pharmacal Research, 24(1), 44-50. http://dx.doi.org/10.1007/BF02976492. PMid:11235811.

Lu, X., Xiong, Z., Li, J., Zheng, S., Huo, T., \& Li, F. (2011). Metabonomic study on 'Kidney-Yang deficiency syndrome'and intervention effects of rhizoma drynariae extracts in rats using ultra performance liquid chromatography coupled with mass spectrometry. Talanta,
83(3), 700-708. http://dx.doi.org/10.1016/j.talanta.2010.09.026. PMid:21147309.

Nishimura, H., Higuchi, O., Tateshita, K., Tomobe, K., Okuma, Y., \& Nomura, Y. (2006). Antioxidative activity and ameliorative effects of memory impairment of sulfur-containing compounds in Allium species. BioFactors (Oxford, England), 26(2), 135-146. http:// dx.doi.org/10.1002/biof.5520260204 PMid:16823099.

Sandroni, P. (2001). Aphrodisiacs past and present: A historical review. Clinical Autonomic Research, 11(5), 303-307. http://dx.doi.org/10.1007/ BF02332975. PMid:11758796.

Shamloul, R. (2010). Natural aphrodisiacs. Journal of Sexual Medicine, 7(1), 39-49. http://dx.doi.org/10.1111/j.1743-6109.2009.01521.x. PMid:19796015.

Shirataki, Y., Motohashi, N., Tani, S., Sunaga, K., Sakagami, H., Satoh, K., Nakashima, H., Kanamoto, T., Wolfard, K., \& Molnar, J. (2001). Antioxidative activity of Allium victorialis L. extracts. Anticancer Research, 21(5), 3331-3339. PMid:11848491.

Sumalatha, K., \& Kumar, A. (2010). Review on natural aphrodisiac potentials to treat sexual dysfunction. International Journal of Pharmacy Practice, 1(1), 6-14.

Tanaka, E., \& Ono, Y. (2018). Whole-leaf fluorescence imaging to visualize in planta fungal structures of Victory onion leaf rust fungus, Uromyces japonicus, and its taxonomic evaluation. Mycoscience, 59(2), 137-146. http://dx.doi.org/10.1016/j.myc.2017.08.013.

Woo, K. W., Moon, E., Park, S. Y., Kim, S. Y., \& Lee, K. R. (2012). Flavonoid glycosides from the leaves of Allium victorialis var. platyphyllum and their anti-neuroinflammatory effects. Bioorganic \& Medicinal Chemistry Letters, 22(24), 7465-7470. http://dx.doi.org/10.1016/j. bmcl.2012.10.043. PMid:23149227. 
Zhang, X., Guan, T., Yang, B., Chi, Z., Wang, Z. Y., \& Gu, H. F. (2018). A novel role for zinc transporter 8 in the facilitation of zinc accumulation and regulation of testosterone synthesis in Leydig cells of human and mouse testicles. Metabolism: Clinical and Experimental, 88, 40-50. http:// dx.doi.org/10.1016/j.metabol.2018.09.002. PMid:30236453.

\section{Supplementary Material}

Supplementary material accompanies this paper.

Table S1 Instruments and equipment.

Table S2 Drugs and reagents.

Table S3 Hormone sampling steps.

Table S4 Steps for determining the activity of SOD in rat serum.

Table S5 Steps for determination of MDA content in rat serum.

Table S6 Determination of nitric oxide synthase in the corpus cavernosum of yin meridian of rats.

This material is available as part of the online article from http://www.scielo.br/CTA 